\title{
ARSITEKTUR RELIGI PESTA TIWAH DAYAK NGAJU SEBAGAI DAYA TARIK WISATA BUDAYA DI KALIMANTAN TENGAH
}

\author{
Carlos Iban $^{1}$, Tuti Elfrida ${ }^{2}$ \\ 1,2. Program Studi Diploma Kepariwisataan, Sekolah Vokasi, Universitas Gadjah Mada \\ Email: ${ }^{1}$ carlosiban@ugm.ac.id, ${ }^{2}$ tutielfrida@ugm.ac.id
}

\begin{abstract}
Abstrak
Kepercayaan masyarakat Dayak Ngaju, khususnya penganut Kaharingan, di Kalimantan Tengah terhadap ruang transenden mengantarkan mereka pada pelaksanaan Pesta Tiwah, ritual penguburan sekunder untuk mengantarkan jiwa orang mati menuju surga yang disebut Lewu Tatau. Pada praktiknya, Pesta Tiwah mewujud pada simbol-simbol sakral sarat makna. Terdapat ketentuanketentuan yang mengatur pelaksanaannya, terlebih pada simbol fisik dan arsitektur religinya. Artikel ini akan mengerucut pada keunikan simbol-simbol pada arsitektur religi Pesta Tiwah yang berpotensi menjadi daya tarik dalam pengembangan produk wisata budaya. Dengan metode kualitatif, data didapatkan melalui wawancara mendalam, observasi partisipatoris, dan dokumentasi. Data digali di dua lokasi yang berbeda, Desa Tumbang Koling, Kabupaten Kotawaringin Timur dan di Desa Ramang, Kabupaten Pulang Pisau, Provinsi Kalimantan Tengah. Simbol sakral pada arsitektur religi Pesta Tiwah meliputi Sapundu dan Sandong. Sapundu mewujud dalam bentuk figur manusia atau binatang, sesuai dengan personifikasi roh sang leluhur. Sapundu berperan dalam menunjukkan jalan bagi jiwa tersebut menuju Lewu Tatau. Selain itu, Sandong merupakan bangunan kubur sekunder berbentuk miniatur rumah panggung yang menyimpan tulang belulang sang leluhur. Pembangunan dan arsitekturnya perlu memperhatikan pondasi, ukuran, tinggi, ukiran, dan ornamennya. Kearifan lokal ini tentunya berpotensi dikembangkan sebagai atraksi wisata budaya. Namun, kesakralan Pesta Tiwah harus tetap terjaga agar terhindar dari komersialisasi dan komodifikasi budaya.
\end{abstract}

Kata kunci: pesta Tiwah, Dayak Ngaju, sapundu, sandong, arsitektur religi, wisata budaya.

\begin{abstract}
Title: The Religious Architecture of Tiwah Feast among Dayak Ngaju as Cultural Tourism Attractions in Central Kalimantan

The belief to a transcendent space among Dayak Ngaju people, especially for Kaharingan believers in Central Kalimantan, leads to the Tiwah Feast, a secondary funeral ceremony to transmit the soul of the dead to a celestial realm called The Lewu Tatau. The Tiwah Feast manifests in many meaningfulness of sacred symbols. There are certain rules in the implementation, particularly on the physical symbols and its religious architectures. This article emphasize the uniqueness of the symbols on the religious architecture of Tiwah Feast, which has the potential to become tourist attraction in the development of cultural tourism products. Using qualitative methods, data obtained through in-depth interviews, participant observation, and documentation, in two different locations, in Tumbang Koling and Ramang Village. Sacred symbols on its religious architecture include Sapundu and Sandong. A sapundu manifests in the form of a human or animal figure, regarding to the personification of the ancestral spirit. It shows the way for the soul towards Lewu Tatau. Meanwhile, Sandong is a secondary burial coffin to put the ancestral bones. The construction and architecture should concern on foundation, size, height, carvings, and ornaments. This local wisdom is potential to be developed as a cultural tourism attraction. However, the sacredness of the Tiwah Feast must be maintained and preserved from cultural commercialization and commodification issues.
\end{abstract}

Keywords: Tiwah feast, Dayak Ngaju, sapundu, sandong, religious architecture, cultural tourism. 


\section{Pendahuluan}

Warisan budaya tidak berwujud (intangible cultural heritage) dan warisan budaya berwujud (tangible cultural heritage) memiliki hubungan yang begitu erat dan sulit untuk terpisahkan. Budaya material merupakan objek dari budaya berwujud yang membutuhkan sentuhan budaya tidak berwujud untuk mengekspresikannya menjadi suatu objek fisik. Warisan budaya berwujud dalam Pesta Tiwah tertuang dalam bentuk arsitektur dari bangunan dan ruang sakral yang menggunakan simbol-simbol religius sebagai ornamen desain. Simbol religius merupakan simbol sakral yang berupa ekspresi material dari aspek-aspek yang bersifat ilahiah dan berada di ruang transenden, ruang yang tidak dapat dijangkau dalam kehidupan di ruang realitas.

Eliade (2012) dalam bukunya berjudul "The Myth of the Eternal Return: Cosmos and History", menggagas bahwa ekspresi material dari suatu simbol religi adalah bentuk 'peniruan' manusia terhadap apa yang telah dilakukan oleh entitas Sang Maha Segalanya (Supreme God), yang di dalam religi Dayak Ngaju disebut Ranying Hatalla Langit. Dalam ritual penghantaran jiwa orang mati di Pesta Tiwah, ada wujud simbol-simbol duniawi yang muncul dalam konteks simbol sakral, contohnya adalah pohon kehidupan, perahu roh, gunung keselamatan, langit ketujuh. Simbolsimbol itu mewakili aspek-aspek dari dimensi ke-Tuhan-an (celestial realm), tetapi mengambil materi subjek dari dimensi di dunia nyata (terrestrial realm). Eliade menyebut objek-objek yang berasal dari celestial realm dengan istilah celestial archetype, objek yang tidak bisa diwujudkan tanpa melalui sistem perlambangan dari simbol duniawi.

Pesta Tiwah bertujuan menghantarkan arwah leluhur menuju alam keabadian yang serba indah dan sempurna (Dyson dan Asharini, 1980: 66). Pesta Tiwah merupakan prosesi penguburan sekunder atau pengangkatan tulangbelulang orang yang sudah meninggal dan dimasukkan ke dalam wadah kubur baru yang disebut sandong. Masyarakat Dayak Ngaju beragama Kaharingan percaya apabila mereka belum melakukan prosesi Pesta Tiwah bagi keluarganya, jiwa dari jenazah akan tetap berada di dunia dan tidak dapat menuju ke Lewu Tatau. Itu sebabnya bagi masyarakat Dayak Ngaju, mengadakan Pesta Tiwah wajib hukumnya, terutama apabila almarhum masih menganut religi Kaharingan.

Masyarakat Dayak Ngaju percaya bahwa jiwa orang mati yang sudah melalui ritual Pesta Tiwah akan menuju ke suatu dimensi keabadian di langit ketujuh. Schiller (1997: 30), menggambarkan Lewu Tatau sebagai "Prosperous Village of Gold Sand, of Diamond Beaches, Carpeted with Silk, of Jasper Pebbles, Heaps of Jasper Beads, Grand Place Where Bones Never Decay Carrying the Burden of the Glorious Flesh, Where the Muscles Never Tire" yang berarti "Desa Sejahtera Berpasirkan Emas, Berpantai Intan, Beralaskan Sutera, Berkerikilkan Manik-Manik, Tempat Yang Megah Di Mana Tulang dan Daging Tidak Akan Membusuk, Di Mana Otot Tidak Akan Pernah Lelah." Lokasi dari dimensi tempat keabadian roh ini terletak di Lewu Tatau, tepatnya di lapisan langit ke tujuh.

Gagasan tentang adanya kehidupan manusia yang ideal di langit ketujuh 
didasarkan pada keyakinan-keyakinan sebagai berikut:

1)
kehidupan merupakan
kosmos; manusia di $\begin{array}{r}\text { tempat } \\ \text { alam }\end{array}$

2) Karena kehidupan di bumi itu dianggap belum ideal, maka masyarakat Dayak Ngaju percaya ada tahapan kehidupan yang lebih ideal;

3) Karena keidealan itu tidak bisa ditemui di bumi (ruang realitas) maka mereka yakin pastilah terdapat di sisi lain kosmos, yaitu non-bumi (ruang transenden), yakni surga yang disebut dengan Lewu Tatau. Lewu Tatau adalah bagian dari sistem perlambangan 'kehidupan ideal di langit ketujuh'. Tanpa adanya bumi, maka konsep Lewu Tatau tidak akan bisa terwujud.

Kebudayaan masyarakat Dayak Ngaju memiliki ekspresi material yang unik dalam merancang bangunan yang memuat simbol-simbol sakral. Dalam prosesi Pesta Tiwah, beberapa unsur visual bangunan didesain dengan konsep perwujudan celestial archetype, yaitu objek-objek yang berasal dari ruang transenden dengan menggunakan simbol dari ruang realitas.

\section{Metode}

Substansi yang dibahas dalam penelitian ini adalah keunikan simbolsimbol pada arsitektur religi Pesta Tiwah yang dapat menjadi daya tarik dalam pengembangan produk wisata di Kalimantan Tengah, khususnya sebagai produk wisata budaya.

\section{Metode Penelitian Kualitatif}

Penelitian ini menggunakan metode penelitian kualitatif. Peneliti terjun ke lapangan, mempelajari suatu proses atau penemuan yang terjadi secara alami, mencatat, menganalisis, menafsirkan dan melaporkan serta menarik kesimpulan-kesimpulan dari proses tersebut. Temuan penelitian dalam bentuk konsep, prinsip, hukum, teori dibangun dan dikembangkan dari lapangan bukan dari teori yang telah ada (Moleong, 2010: 4-6).

\section{Metode Pengumpulan Data}

Data dalam penelitian ini terdiri dari dua macam, yaitu data primer dan data sekunder. Data primer merupakan sumber data yang diperoleh langsung dari sumber asli tanpa melalui media perantara. Data primer dapat berupa opini subjek secara individual atau kelompok, hasil observasi terhadap suatu benda (fisik), kejadian atau kegiatan. Dalam penelitian ini, pengumpulan data primer menggunakan metode observasi partisipatoris (participant observer), informan penelitian, wawancara mendalam (in-depth Interview), dan dokumentasi.

Data sekunder merupakan sumber data penelitian yang diperoleh secara tidak langsung melalui media perantara atau diperoleh dan dicatat oleh pihak lain. Data sekunder umumnya berupa bukti, catatan atau laporan historis yang telah tersusun dalam arsip (data dokumenter) yang dipublikasikan dan yang tidak dipublikasikan. Dalam penelitian ini, data sekunder dikumpulkan dengan metode studi literatur.

\section{Metode Analisis Data}

Analisis data kualitatif dalam penelitian ini menggunakan Interactive Model Analysis menurut Miles, Huberman dan Saldana (2012: 16) dan Triangulation menurut Denzin dan Lincoln (2011). Dalam penelitian kualitatif, proses pengumpulan dan analisis data tidak dapat dipisahkan. 
Pengumpulan data ditempatkan sebagai komponen yang merupakan bagian integral dari kegiatan analisis data. Analisis data dalam penelitian kualitatif dilakukan sejak awal kegiatan penelitian sampai akhir penelitian.

Data yang terkumpul kemudian dianalisis menggunakan Interactive Model Analysis, yaitu data reduction, data display, dan conclusion drawing. Dalam tahap data reduction, dilakukan dialog data dengan mengelompokan data menjadi tiga kategori tema, yaitu tema kebudayaan berwujud (tangible culture); tema kebudayaan tidak berwujud (intangible culture); dan tema bentang budaya (cultural landscape).

Proses triangulasi dalam penelitian ini menggunakan pengamatan dan pencocokan antara berbagai data yang berasal dari informan, wawancara mendalam, dan observasi partisipatoris. Untuk menjamin keakuratan data, observasi partisipatoris dilakukan di dua lokasi penelitian, yaitu di Desa Tumbang Koling, Kabupaten Kotawaringin Timur dan di Desa Ramang, Kabupaten Pulang Pisau, Provinsi Kalimantan Tengah.

Berikutnya, dilakukan uji silang terhadap hasil pengumpulan data tentang tema Pesta Tiwah untuk memastikan tidak ada informasi yang bertentangan antara data informan, data wawancara mendalam, dan data observasi partisipatoris. Setelah itu, hasil yang telah diperoleh perlu diuji lagi dengan informan-informan lainnya sampai tidak ada lagi perbedaanperbedaan yang perlu dikonfirmasikan kepada informan (Gambar 1).

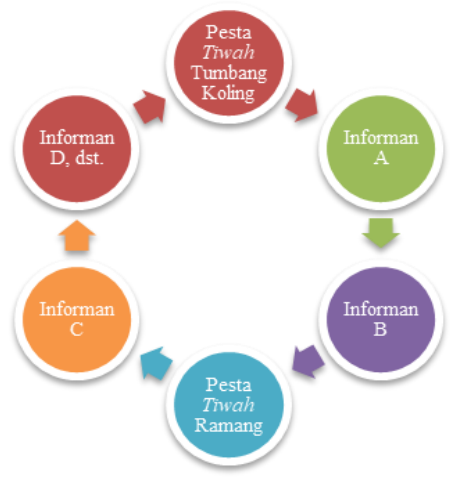

Gambar 1. Proses triangulasi data Sumber: Adaptasi dari Denzin dan Lincoln, 2011

\section{Hasil dan Pembahasan}

Arsitektur religi dalam Pesta Tiwah merupakan pencampuran antara aspekaspek yang berasal dari ruang transenden dunia atas dan dunia bawah, di mana keduanya merupakan bagian dari konsep Celestial Realm, yaitu aspek-aspek yang terkait dengan konsep teologis Kaharingan dan kosmologis Dayak Ngaju, dan aspekaspek yang berasal dari kehidupan manusia di ruang realitas atau Terrestrial Realm, yaitu aspek-aspek yang terkait dengan perwujudan fisik bangunan religi tersebut.

Beberapa faktor dari ruang realitas yang mempengaruhi bentuk arsitektur meliputi:

1) Kondisi geografis

Sebagai faktor kekuatan yang bersifat relatif konstan di satu tempat tertentu; terbentuk karena perbedaan karakter alam. Termasuk di dalamnya adalah kondisi iklim tropis di Kalimantan Tengah, luasnya hutan hujan tropis, dengan sungai yang memiliki multifungsi khususnya sebagai sarana aksesibilitas. Sungai diyakini sebagai ruang sakral dan mediator penting bagi proses menuju kehidupan baru 
pada dimensi transenden. Proses kembalinya jiwa manusia ke alam roh melalui Pesta Tiwah harus dilalui dengan menempuh suatu perjalanan kosmik ke hulu sungai hingga menuju ke langit ketujuh. (Gambar 2 dan 3).

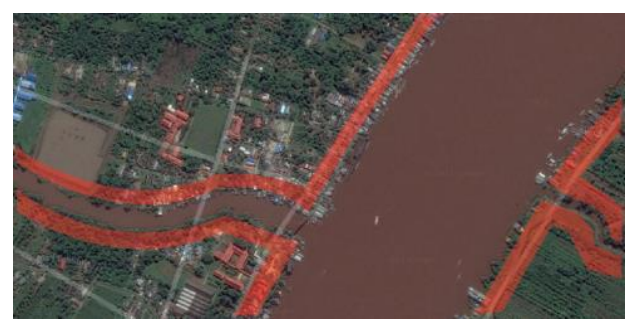

Gambar 2. Pola pemukiman di Kalimantan Tengah sebagian besar berada di tepian sungai (area berwarna merah) Sumber: Analisis peneliti, 2017

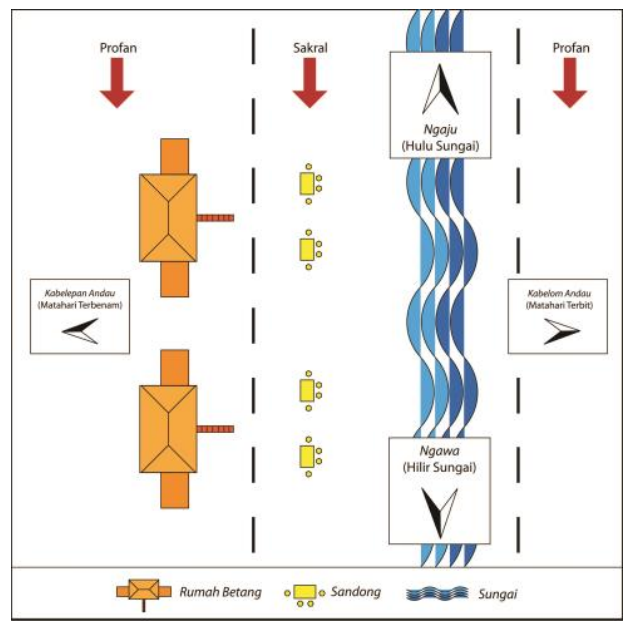

Gambar 3. Ilustrasi pembagian ruang sakral dan profan di pemukiman Dayak Ngaju

Sumber: Analisis peneliti, 2017

Masyarakat Dayak Ngaju percaya bahwa arah hulu sungai (ngaju) dan matahari terbit (kabeloman andau) adalah arah yang lebih baik dari arah hilir sungai (ngawa) ataupun arah matahari terbenam (kabelepan andau). Namun demikian lingkungan fisik suatu wilayah juga ikut menentukan arah hadap suatu bangunan. Letak sungai menjadi prioritas utama dalam menentukan arah hadap bangunan, karena sungai memiliki multifungsi sebagai sumber kehidupan.

2) Penggunaan teknologi

Penggunaan teknologi merupakan faktor yang berpengaruh di satu lingkungan sosial dan bersifat relatif cepat untuk berubah. Perkembangan teknologi memungkinkan berbagai bentuk arsitektur tradisional mengalami proses transformasi.

3) Sosial budaya

Merupakan faktor yang terbentuk karena perkembangan sosial budaya masyarakat yang selalu berubah mengikuti perkembangan kondisi masyarakat dalam kehidupan sehari-hari.

Lokasi di mana faktor sosial budaya masyarakatnya bersifat lebih homogen dan memiliki akar budaya yang kuat, proses inkulturasi berjalan lebih kuat dibandingkan dengan di lokasi di mana faktor sosial budaya masyarakatnya lebih heterogen seperti di kota-kota besar. Konsepsi religi dari Pesta Tiwah kemudian diejawantahkan dalam bentuk materi fisik.

Masyarakat Dayak Ngaju percaya bahwa kehadiran simbol-simbol dari ruang transenden yang dimunculkan di ruang realitas dengan mediator ritual sakral Pesta Tiwah diharapkan memberi ketentraman bagi kehidupan manusia di bumi dan 'kehidupan' roh di Lewu Tatau. Ekspresi material dari ritual penguburan sekunder tersebut berwujud celestial archetype, yaitu struktur yang disebut sapundu dan sandong (Gambar 4). 


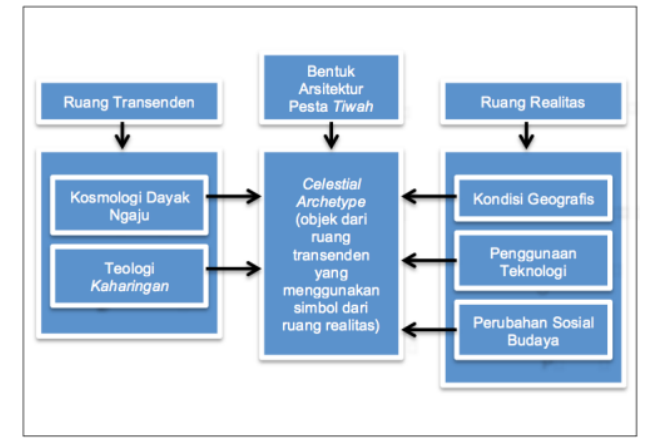

Gambar 4. Kekuatan pembentuk arsitektur religi Pesta Tiwah

Sumber: Analisis peneliti, 2017

\section{Sapundu}

Sapundu merupakan struktur berbentuk figur manusia atau binatang yang terbuat dari kayu ulin atau borneo ironwood (Eusideroxylon zwageri) sebagai personifikasi dari roh leluhur yang disebut dengan sangiang. Wujud dari sapundu mengacu ke sifat dan tingkah laku dari sangiang tersebut. Roh leluhur yang diwujudkan dalam ekpresi material berbentuk sapundu berguna untuk menemani dan memberi petunjuk jalan bagi jiwa yang diTiwah-kan dalam perjalanan kosmik menuju ke Lewu Tatau. Apabila yang di-Tiwah-kan adalah laki-laki, maka sapundu berwujud perempuan yang dibuat, begitu pula sebaliknya bila perempuan yang akan di-Tiwah-kan makan sapundu laki-laki lah yang dibuat. Dalam beberapa kasus, sapundu juga dibuat dalam wujud binatang dan mahluk manusia setengah siluman, tergantung dari bentuk sangiang yang akan membantu perjalanan kosmik tersebut.

Sapundu digunakan untuk menambatkan hewan kurban selama Pesta Tiwah, didirikan di area terbaik di suatu desa dan bertahan hingga ratusan tahun, sebagai pengingat kemeriahan Pesta Tiwah di masa lampau serta bukti bahwa tanggung jawab keluarga kepada leluhurnya telah ditunaikan. Hewan kurban yang diikat di sapundu harus berlawanan berjenis kelamin dengan sapundu.

Berdasarkan bentuknya, sapundu dibedakan menjadi enam jenis, yaitu:

1) Sapundu hatue, berwujud laki-laki yang membawa alat persenjataan (Gambar 5 dan 6). Senjata yang digunakan biasanya adalah dohong (senjata tajam berupa parang kecil), lunju (tombak), mandau (parang), dan talawang (tameng kayu).
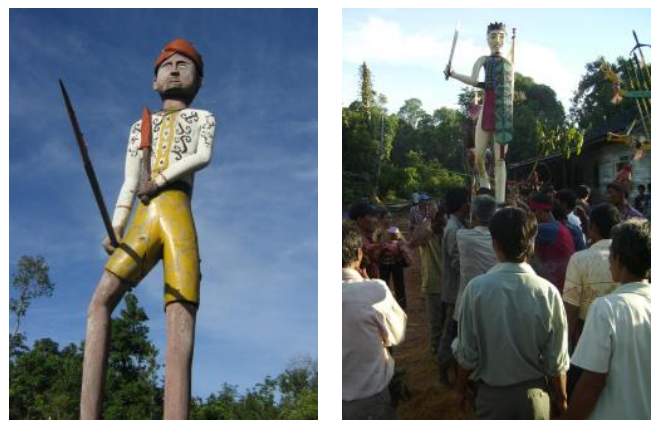

Gambar 5. (Kiri) Sapundu hatue yang berwujud laki-laki membawa dohong (senjata parang kecil) dan lunju (tombak) Sumber: Dokumentasi peneliti, 2017

Gambar 6. (Kanan) Sapundu hatue yang berwujud laki-laki membawa mandau dan talawang

Sumber: Dokumentasi peneliti, 2017

2) Sapundu bawi, berwujud perempuan, biasanya membawa wadah atau bayi/anak kecil. Wadah yang dibawa berupa tempat sirih, guci, mangkok, tempayan minum, dan wadahwadah kecil lainnya (Gambar 7 dan 8). 

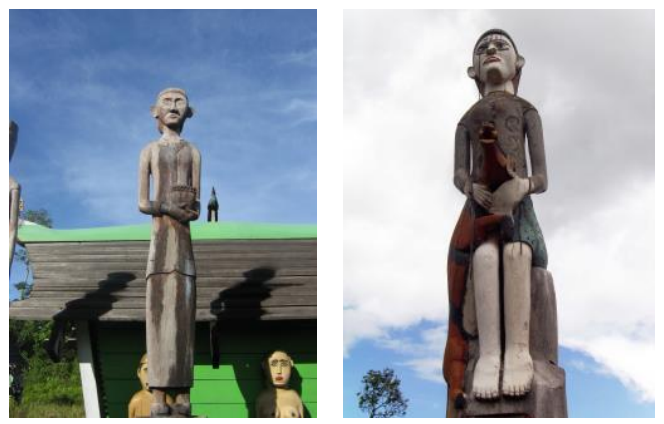

Gambar 7. (Kiri) Sapundu bawi yang berwujud perempuan membawa tempat sirih

Sumber: Dokumentasi peneliti, 2017

Gambar 8. (Kanan) Sapundu bawi yang berwujud perempuan membawa tempayan minum

Sumber: Dokumentasi peneliti, 2017

3) Sapundu sambali, berwujud variasi tipe binatang dan mahluk mistis, misalnya anjing dan buaya. Ada beberapa ragam mahluk mistis yang dijadikan figur sapundu, seperti wujud siluman manusia berkepala buaya (Gambar 9).

4) Sapundu haramaung, berwujud macan dahan (Gambar 10).
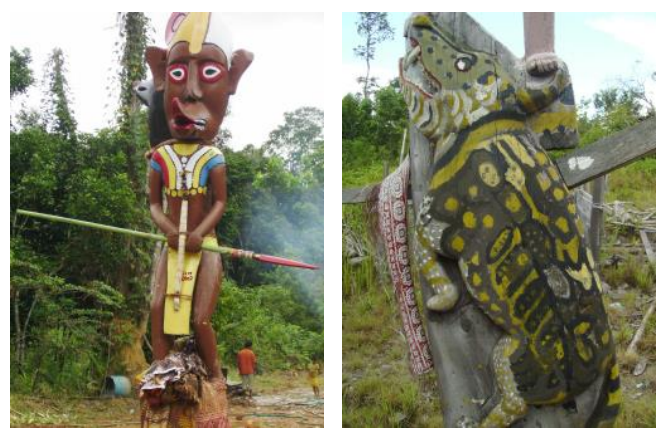

Gambar 9. (Kiri) Sapundu sambali berwujud mahluk mistis manusia siluman. Sumber: Dokumentasi peneliti, 2017

Gambar 10. (Kanan) Sapundu haramaung yang berwujud macan dahan (Neofelis diardi borneensis)

Sumber: Dokumentasi peneliti, 2017

5) Sapundu embak bakas, berwujud laki-laki tua yang membawa benda, seperti padi di sekeliling lehernya atau membawa wadah kecil (Gambar 11).

6) Sapundu rahu nyampang, berwujud sepasang laki-laki dan perempuan yang sedang bersetubuh (Gambar 12).

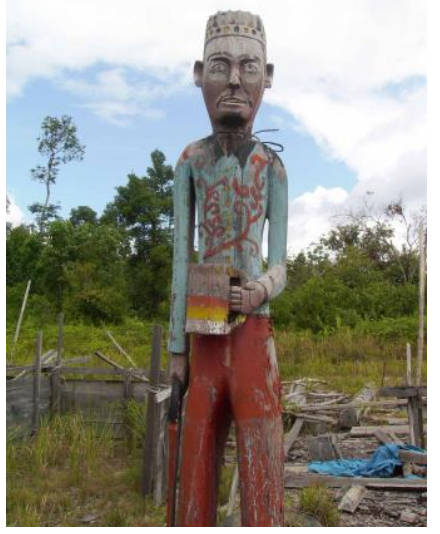

Gambar 11. Sapundu embak bakas yang berwujud laki-laki tua yang membawa cangkir dan dohong (senjata parang kecil) Sumber: Dokumentasi peneliti, 2017

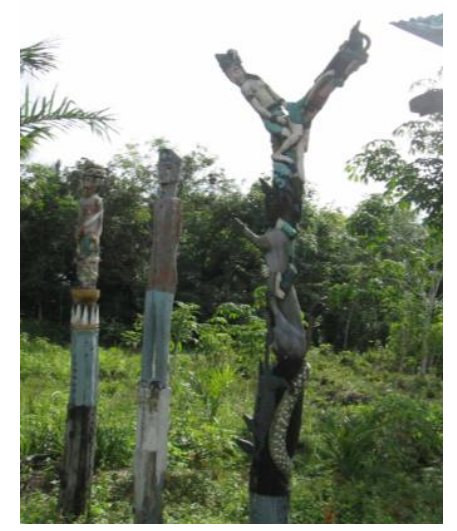

Gambar 12. Sapundu rahu nyampang berwujud berwujud sepasang laki-laki dan perempuan yang sedang bersetubuh Sumber: Dokumentasi peneliti, 2017

\section{Sandong}

Sandong atau sandung merupakan bangunan kubur sekunder berwujud miniatur rumah panggung. Di dalam sandong tersimpan tulang-belulang manusia yang telah melewati ritual 
sakral Pesta Tiwah. Seperti sapundu, sandong idealnya terbuat dari kayu ulin. Dari hasil olah data berdasarkan observasi dan sumber informan, sandong di Kalimantan Tengah terbagi menjadi:

1) Sandong tunggal, wadah kubur sekunder yang berdiri di satu tiang atau satu pondasi kaki penopang.

2) Sandong keratun, wadah kubur sekunder yang berdiri di empat tiang atau empat pondasi kaki penopang (Gambar 13).

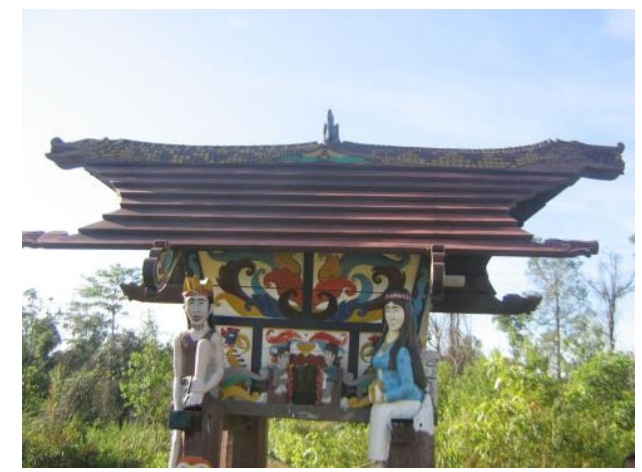

Gambar 13. Sandong keratun dengan ornamen Jata (naga air) di bagian atap dan dijaga oleh sepasang patung sangiang (leluhur)

Sumber: Dokumentasi peneliti, 2017

3) Sandong kariring, wadah kubur sekunder yang berdiri di dua tiang atau dua pondasi kaki penopang.

4) Sandong raja, wadah kubur sekunder berukuran raksasa yang berdiri di enam hingga sembilan tiang penopang.

5) Sandong munduk, wadah kubur sekunder yang diletakkan di atas tanah, tanpa tiang penyangga, umumnya untuk mengubur mereka yang meninggal karena terbunuh atau kecelakaan (Gambar 14).

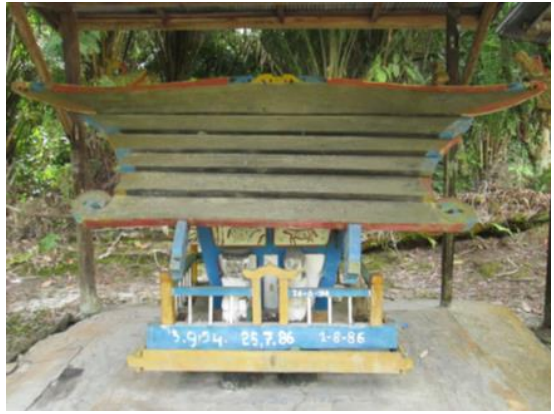

Gambar 14. Sandong munduk di Bukit Rawi, Palangkaraya

Sumber: Dokumentasi peneliti, 2017

Desain sandong memiliki model mirip seperti rumah tradisional mini, lengkap dengan atap, pintu kecil, dan jendela. Perwujudan dari seekor burung berukuran kecil sering ditempatkan di atap wadah kubur ini. Informan mengatakan bahwa burung ini disebut piak liau, yang nantinya akan menjadi milik salumpuk liau (jiwa orang yang telah meninggal) di Lewu Tatau.

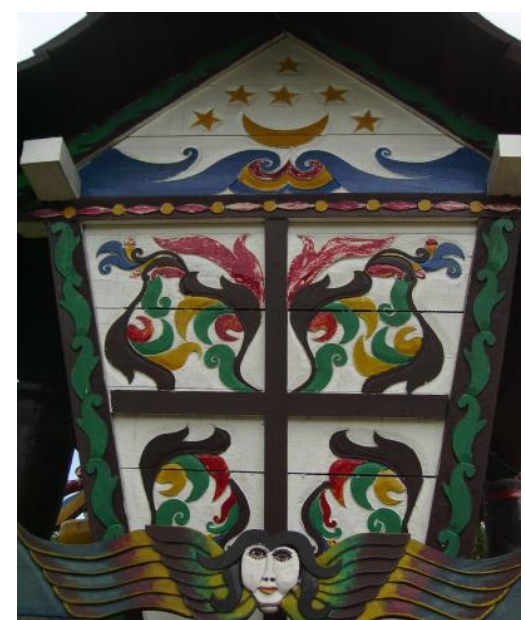

Gambar 15. Ornamen bulan dan bintang di sisi atas dan sangiang berwujud manusia dengan dua sayap di sisi bawah sandong Sumber: Dokumentasi peneliti, 2017

Ornamen bulan dan bintang-bintang sering dicat atau diukir di sisi sandong, sedangkan matahari digambarkan di sisi berlawanan (Gambar 15 dan 16). Simbol ini perwujudan dari jiwa-jiwa yang harus lulus semua tanda-tanda kosmologis dalam perjalanan mereka 
menjadi roh yang akan bersemayam di Lewu Tatau.

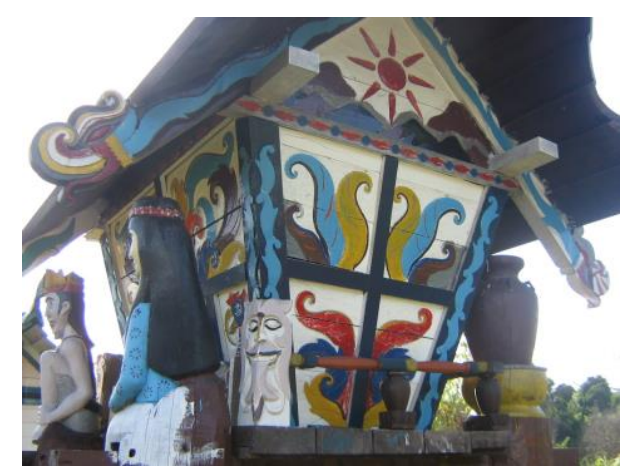

Gambar 16. Ornamen matahari yang terletak di sisi samping bagian atas sandong Sumber: Dokumentasi peneliti, 2017

Ukiran sandong diisi dengan berbagai ornamen celestial achetype. Hiasan dengan motif burung tingang yang melambangkan dunia atas, sedangkan ornamen berwujud Jata (naga air), siluman, dan hewan atau mahlukmahluk menyeramkan yang ada di mitos Dayak Ngaju sebagai simbol dunia bawah.

Sandong juga memiliki variasi tinggi dan ukuran, beberapa wadah kubur menempel di atas tanah, yang lain sampai enam meter atau lebih; ada yang dibangun untuk tulang-tulang bagi satu orang, yang lain untuk lima puluh orang atau lebih. Saat berlangsungnya Pesta Tiwah, secara umum masyarakat Dayak Ngaju DAS Kahayan lebih sering membuat sandong berukuran besar yang mampu menyimpan tulang-belulang bagi puluhan kerabat, sedangkan masyarakat Dayak Ngaju DAS Katingan lebih sering membuat sandong dengan ukuran yang kecil.

Alasan mengapa seorang individu yang telah di-Tiwah-kan tetap ditempatkan sendirian di dalam sandong tampaknya bervariasi. Beberapa informan menyatakan bahwa wadah kubur dari jenis sandong tunggal dibangun terutama bagi orang-orang yang telah meninggal dengan kematian yang tidak wajar. Sumber lain menyatakan bahwa wadah kubur jenis ini dibangun untuk individu-individu dengan status bangsawan dan memastikan bahwa bekal kubur mereka tidak dicuri.

\section{Pesta Tiwah dan Wisata Budaya}

Pesta Tiwah sebagai living heritage merupakan bentuk kearifan mayarakat Dayak Ngaju yang memiliki potensi untuk dikembangkan sebagai produk pariwisata di Kalimantan Tengah dan dapat menjadi daya tarik baru bagi wisatawan baik luar dan dalam negeri, khususnya bagi segmentasi wisatawan minat khusus yang memiliki ketertarikan tertentu pada keunikan warisan budaya. Nilai kearifan dari Pesta Tiwah yang menjadi warisan budaya bagi masyarakat Dayak Ngaju di Kalimantan Tengah memiliki nilai budaya tinggi, baik itu yang berbentuk tradisional maupun berbentuk monumental. Selain itu, Pesta Tiwah sebagai warisan budaya memiliki daya tarik wisata yang kuat, pengembangan Pesta Tiwah sebagai produk pariwisata tidak selamanya memerlukan modal ekonomi (economic capital), tetapi memerlukan suatu product-driven berupa modal budaya (cultural capital) yang kuat.

Industri pariwisata dengan kebudayaan sebagai objeknya telah membawa paradigma baru, di mana sumber daya budaya yang dulunya diproduksi dan konsumsi masyarakat, sekarang telah bergeser menjadi konsumsi publik, khususnya bagi wisatawan. Paradigma baru tersebut merupakan 'komersialisasi budaya' atau 'budaya yang dijual'. Komersialisasi budaya menyajikan sumber daya budaya yang tidak dilakukan dalam praktik yang biasa dilakukan dalam kehidupan 
bermasyarakat, tetapi disesuaikan dengan waktu dan daya beli wisatawan yang menyaksikannya. Bentuk komersialisasi budaya itu tidak hanya terjadi dalam adat istiadat saja, tetapi meliputi semua unsur kebudayaan yang banyak kaitannya dengan kegiatan kepariwisataan, seperti misalnya seni patung, seni lukis, busana, makanan tradisional dan banyak bentuk sumber daya budaya lainnya yang mampu memberikan daya tarik bagi wisatawan. Komersialisasi budaya mengakibatkan suatu bentuk sumber daya budaya yang awalnya berada di ruang privat dan memiliki kesakralan, mulai bergeser ke ruang publik yang profan dan memanfaatkan daya tarik sumber daya budaya tersebut menjadi nilai ekonomis yang dapat dijual.

Durkheim (2012: 1-3) mendefinisikan bahwa kesakralan atau the sacred merupakan pengalaman komunal masyarakat yang menjadi lambang kebersatuan transenden yang dimanifestasikan dalam simbol-simbol masyarakat, sementara profan atau the profane merupakan pengalaman individual yang dianggap lebih rendah dari pengalaman sakral. Konsep Durkheim yang melihat keduanya berdasarkan kesepakatan bersama dalam suatu masyarakat sedikit berbeda dengan pemikiran Eliade.

Menurut Eliade (2012), profan merupakan aspek kehidupan seharihari yang sering dilakukan secara teratur, acak, dan sebenarnya tidak terlalu penting, sementara sakral adalah wilayah yang supranatural, sesuatu yang di luar normal, tidak mudah dilupakan, dan penting. Dengan kata lain, profan tidak menjadi penentu utama dalam hidup manusia sementara sakral menjadi penentu keberadaan manusia.
Masyarakat Dayak Ngaju sendiri memandang kehidupan merupakan suatu kesatuan holistik. Mereka mempercayai bahwa kehidupan di dunia ini adalah sesuatu yang fana dan tidak ideal. Hanya melalui Pesta Tiwah saja lah mereka akan mencapai bentuk 'kehidupan' yang sesungguhnya, suatu keabadian di dimensi kosmos lain yang dianggap lebih ideal. Adanya pembagian sakral dan profan merupakan cara pandang dari masyarakat luar yang menilai cara masyarakat Dayak Ngaju dalam praktik dan interaksi sosio-religi mereka secara vertikal dengan Sang Pencipta maupun secara horizontal, dengan sesama masyarakat.

Kesakralan atau suatu bentuk kepercayaan supranatural komunal terhadap suatu objek dipercaya oleh masyarakat Dayak Ngaju ada dalam setiap unsur kehidupan dan telah menjadi bagian dari kehidupan seharihari mereka. Semua dilakukan di dunia 'sementara' ini dipandang suci, kudus, sakral. Mulai dari kelahiran, bercocok tanam, berladang, berburu, perkawinan, membangun rumah, dan kematian, semuanya memiliki konsep kesakralan, hanya saja struktur stratifikasinya yang berbeda-beda. Dari semuanya itu, ritual adat Pesta Tiwah merupakan ritual paling sakral yang menempati posisi puncak dari berbagai ritual religi pada masyarakat Dayak Ngaju di Kalimantan Tengah.

Domain sakral dan profan di dalam penelitian ini ditinjau dari hasil analisis elemen-elemen sumber daya Pesta Tiwah sebagai product-driven daya tarik wisata. Berikutnya, elemenelemen tersebut akan dikategorikan menurut substansi prosesi ritual. Domain sakral adalah elemen yang ada di dalam konteks prosesi Pesta Tiwah, sedangkan domain profan adalah 
elemen yang berada di luar konteks prosesi Pesta Tiwah.

Dalam mengembangan daya tarik wisata pada Pesta Tiwah, perlu adanya delineasi yang dapat menggambarkan perbedaan antara daya tarik Pesta Tiwah dalam ruang lingkup sakral dan daya tarik profan yang berada di luar ritus yang sakral. Pesta Tiwah merupakan bentuk living heritage yang masih dipraktikkan secara turuntemurun oleh masyarakat Dayak Ngaju dari masa lampau hingga masa sekarang, sehingga dalam pengembangannya sebagai produk wisata, komponen sakral dari Pesta Tiwah tidak dapat dimodifikasi sebagai objek yang menyesuaikan aspek permintaan, karena komponen sakral tersebut merupakan roh yang menjadi daya tarik utama Pesta Tiwah.

Unsur penting dalam pengembangan komponen sakral sebagai produk wisata adalah perlu adanya mitigasi dampak negatif pariwisata pada kebudayaan, yaitu menghindari timbulnya komersialisasi budaya Pesta Tiwah yang awalnya di ruang privat masyarakat dan berada di domain sakral, mulai bergeser ke ruang publik yang profan dan mengeksploitasi daya tarik sumber daya budaya tersebut menjadi nilai ekonomis yang dapat dijual.

Komponen daya tarik yang berada dalam domain profan akan menjadi lebih bebas pengembangan dan pengunaannya dibandingkan dengan daya tarik yang berada dalam domain sakral. Komodifikasi dan komersialisasi budaya dapat diakses seluasnya dalam koridor pariwisata. Pemanfaatan daya tarik domain profan berdasarkan hasil analisis adalah handycraft atau pengolahan kerajinan menjadi souvenir, gastronomy atau ragam kuliner, dan leisure atau aktivitas di waktu senggang.

\section{Kesimpulan}

Setiap agama atau kepercayaan meyakini adanya ruang transenden, sebuah ruang non-duniawi yang bersifat ilahiah. Pesta Tiwah yang dimiliki oleh masyarakat Dayak Ngaju beragama Kaharingan di Kalimantan Tengah merupakan ritual penguburan sekunder yang dimaksudkan untuk menghantarkan arwah leluhur menuju alam keabadian, yakni Lewu Tatau. Sapundu dan Sandong lah yang kemudian menjadi elemen penting sekaligus bagian dari tangible haritage dalam rangkaian Pesta Tiwah.

Sebagai bentuk dari living heritage, Pesta Tiwah layak dijaga kelestariannya. Langkah pengembangan Pesta Tiwah menjadi atraksi wisata budaya mampu menjadi upaya dalam menjaga ritual tersebut terus eksis, baik rangkaian ritual maupun simbol fisik yang sakral. Jika demikian, Pesta Tiwah akan bertransformasi menjadi produk yang dikonsumsi publik. Isu komersialisasi dan komodifikasi budaya pun muncul seiring dijadikannya Pesta Tiwah sebagai daya tarik wisata. Dampaknya, unsur sakral dari Pesta Tiwah dapat memudar, dan menyisakan ke-profan-annya.

Dalam pengembangan wisata budaya, masyarakat Dayak Ngaju baiknya memberi batas antara wilayah sakral dan profan. Dalam artian, terdapat domain yang bisa diakses penuh oleh wisatawan dan domain yang hanya bisa diakses secara terbatas oleh wisatawan dan dikendalikan penuh oleh masyarakat lokal Dayak Ngaju.

Selanjutnya, pengembangan Pesta Tiwah dalam bingkai wisata budaya tidak terfokus pada upaya menarik 
wisatawan, melainkan lebih pada menjaga esensi, baik spiritual maupun non-spiritual, dan kelestarian ritual keagamaan tersebut.

\section{Daftar Pustaka}

Denzin, N., \& Lincoln, Y. (2011). The Sage handbook of qualitative research $\left(4^{\text {th }} \quad e d.\right)$. Thousand Oaks, California: Sage.

Durkheim, E. (2012). The elementary forms of religious life. Mineola, New York: Dover Publication, Inc.

Dyson, L., \& Asharini, M. (1980). Tiwah upacara kematian pada masyarakat Dayak Ngaju di Kalimantan Tengah. Jakarta: Proyek Media Kebudayaan Jakarta, Direktorat Jenderal Kebudayaan, Departemen Pendidikan dan Kebudayaan.

Eliade, M. (2012). The myth of the eternal return: Cosmos and history. Princetown, New Jersey: Princeton University Press.

Miles, M., Huberman, A., \& Saldana, J. (2014). Qualitative data analysis, a method sourcebook $\left(3^{\text {th }}\right.$ ed.). Thousand Oaks, California: Sage.

Moleong, L. (2010). Metodologi penelitian kualitatif. Bandung: Remaja Rosda Karya.

Schiller, A. (1997). Religious change and cultural identity among the Ngaju of Indonesia. Madison Avenue, New York: Oxford University Press. 